\title{
Comparison of the n-Alkanes and Polycyclic Aromatic Hydrocarbons Concentrations in the Atmosphere during the Preparation of Warm and Hot Mixtures Asphalt for Pavements
}

\author{
Rosângela Motta, ${ }^{*, a}$ Pérola C. Vasconcellos, ${ }^{b}$ Liedi Bernucci, ${ }^{a}$ \\ Simone G. Ávila ${ }^{b}$ and Talita Cornetti ${ }^{a}$ \\ ${ }^{a}$ Departamento de Engenharia de Transportes, Escola Politécnica, Universidade de São Paulo, \\ Av. Prof. Almeida Prado, trav. 2, 83, Cidade Universitária, 05508-070 São Paulo-SP, Brazil \\ ${ }^{b}$ Instituto de Química, Universidade de São Paulo, Av. Prof. Lineu Prestes, 748, Bloco 8 superior, \\ Cidade Universitária, 05508-900 São Paulo-SP, Brazil
}

\begin{abstract}
O asfalto é utilizado na produção de misturas asfálticas a quente (HMA) para a pavimentação e, devido às altas temperaturas empregadas, gera fumos que contêm n-alcanos e hidrocarbonetos policíclicos aromáticos (HPAs). As misturas asfálticas preparadas em temperaturas mais baixas, como as misturas asfálticas mornas (WMA), podem contribuir na redução das emissões daqueles compostos e economizar energia. Este trabalho investiga os n-alcanos e os HPAs nas partículas totais em suspensão durante a preparação de uma WMA, em comparação com uma HMA, em laboratório. Os resultados mostraram que os n-alcanos da WMA e da HMA apresentaram $\mathrm{C}_{\text {máx }}$ no $n-C_{26}$ e n- $C_{28}$, respectivamente, e o teor de n-alcanos total foi maior na HMA do que na WMA. Ademais, verificou-se que o benzo[b]fluoranteno e benzo[a]antraceno constituíam os maiores HPAs na WMA, enquanto as temperaturas mais altas da HMA volatilizaram todos seus grandes HPAs, demonstrando maior potencial de exposição por inalação.
\end{abstract}

Asphalt binder is used in the production of hot mixes asphalt (HMA) for paving and, due to the high temperatures used, generates fumes thatcontainn-alkanes and polycyclic aromatic hydrocarbons (PAH). Asphalt mixes prepared at lower temperatures, such as warm mixes asphalt (WMA), may contribute to reduce the emissions of those compounds and save energy. This paper investigatesn-alkanes and PAH in the total suspended particles during the preparation of WMA, in comparison with HMA, in laboratory. The results showed that the n-alkanes of the WMA and HMA presented $\mathrm{C}_{\max }$ at $\mathrm{n}-\mathrm{C}_{26}$ and $\mathrm{n}-\mathrm{C}_{28}$, respectively; also, the total content of $\mathrm{n}$-alkanes was higher for the HMA than forthe WMA. Besides, benzo[b]fluoranthene and benzo[a]anthracene were the major PAH in the WMA, while the higher temperatures of the HMA were observed to volatilize all larger $\mathrm{PAH}$, demonstrating higher potential of inhalation exposure.

Keywords: warm mix asphalt, hot mix asphalt, PAH, n-alkanes

\section{Introduction}

One of the most used pavement materials as wearing courses combines asphalt binder (bituminous material) and mineral aggregate, both heated, to produce hot mixes asphalt (HMA). High temperatures are necessary in order to provide enough workability and appropriate coating of the aggregate by the asphalt binder (usually about 160 to $\left.180^{\circ} \mathrm{C}\right), 1,2$ but vapors are released from the bituminous material as the temperature increases. These vapors

*e-mail: rosangela.motta@gmail.com condensate in contact with cooler air and turn into asphalt fumes. The chemical composition of those asphalt vapors and fumes is variable and depends on some factors, such as crude oil origin, type of asphalt binder, mixing time and temperature. ${ }^{3}$ Besides, it is known that the heating of petroleum products originates pollutants such as $\mathrm{n}$-alkanes and polycyclic aromatic hydrocarbons (PAH).,5

The distribution of the homologues series of n-alkanes presents anthropogenic and biogenic emissions. In asphalt mix production, the most volatile species are preferentially emitted and only low concentrations of highly numbered $n$-alkanes are observed. ${ }^{5}$ The branched alkane 
pristane (2,6,10,14-tetramethylpentadecane) and phytane (2,6,10,14-tetramethylhexadecane) found in atmospheric samples confirm the presence of petroleum residue. ${ }^{6}$

PAH is a class of complex organic chemicals, including carbon and hydrogen with a fused ring structure containing at least two benzene rings. Some PAH are often considered potentially dangerous to human health, due to their carcinogenic and/or mutagenic properties. Therefore, the United States Environmental Protection Agency (USEPA) has classified $16 \mathrm{PAH}$ as priority pollutants to be prevented. ${ }^{7}$

As the temperature increases, $n$-alkanes and PAH concentrations are higher. Thus, the temperature is an important issue to control asphalt binder emissions, ${ }^{8,9}$ and hence asphalt fumes generated at higher temperatures are probably more hazardous than those produced at lower temperatures. ${ }^{3}$ In this context, asphalt mixes prepared at lower temperatures may contribute to reduce n-alkanes and PAH emissions.

In the last decade, several paving technologies involving processes and products for lowering HMA temperatures were developed, in order to reduce emissions and to save energy, yet maintaining the same performance. These techniques have been generically named warm mixes asphalt (WMA) and usually allow reducing HMA temperatures around $30{ }^{\circ} \mathrm{C} .{ }^{10}$ WMA technologies basically consist in foaming the asphalt binder and/or adding chemical additives into the asphalt binder or into the asphalt mixture, thus still providing sufficient workability and appropriate coating at lower temperatures throughout the paving process. ${ }^{1,10}$

The mixing process is the paving phase in which temperatures are higher, thus n-alkanes and PAH emissions may also be intenser.The purpose of this paper is to investigate the composition of the asphalt fumes, regarding $\mathrm{n}$-alkanes and priority PAH collected in the total suspended particles (TSP), during the mixing process in the laboratory, comparing WMA (chemical additive technique) and a conventional HMA. Pollutants were extracted from quartz fiber filters, and n-alkanes and PAH were analyzed by gas chromatography. This is a preliminary study in asphalt emissions and further research on this topic has been taking place.

\section{Experimental}

\section{Materials}

Crushed granite stones and lime were used as aggregate, in which four aggregate sizes were combined to compose a dense-graded distribution $(14 \%$ of $0 / 12.5 \mathrm{~mm}, 45 \%$ of $0 / 9.5 \mathrm{~mm}, 39.5 \%$ of $0 / 4.75 \mathrm{~mm}$ of granite stones and $1.5 \%$ of hydrated lime).
The asphalt binder was processed by Replan-Petrobras Refinery in Brazil (São Paulo State) and was classified by penetration grade as 30/45.

The chemical additive for WMA used in this study (commercially named as Gemul XT14) is composed of synthetic amides in a liquid form. This product does not interfere with the asphalt consistency properties (viscosity, penetration and melting point), but acts as a surfactant at the interface aggregate/asphalt to promote workability and coating in the WMA. The surfactant was added to the hot asphalt binder and then blended during 15 min with an electric blender, prior to the WMA mixing process.

Four asphalt mixes samples, each containing $5000 \mathrm{~g}$, were prepared for the experimental study, in which the aggregate corresponded to $95 \%$ (or $4750 \mathrm{~g}$ ) and the asphalt binder corresponded to $5 \%$ (or $250 \mathrm{~g}$ ). These proportions were defined as usual for paving in Brazil, by the Marshall design method. ${ }^{1,2}$ The additive rate was $0.3 \%$ of the mass of the asphalt binder, which corresponded to $0.75 \mathrm{~g}$ in each WMA sample.

\section{Methods}

\section{Mixing temperature}

As usual, the suitable mixing temperature for HMA was provided by the asphalt binder supplier, based on the viscosity of that bituminous material. ${ }^{1}$ For the WMA, the mixing temperature was assumed to be $25^{\circ} \mathrm{C}$ lower than the HMA.

Prior to the mixing process, asphalt binder and aggregate were both heated; the temperature of the asphalt binder was the same for the HMA and the WMA, but the temperature of the aggregate was 30 to $35^{\circ} \mathrm{C}$ lower for the WMA. Usually, WMA techniques consider reducing aggregate temperature, since this material is the largest part of an asphalt mixture and requires a large amount of energy to be dried and heated. ${ }^{10}$ Table 1 indicates the temperature used for heating and mixing the HMA and the WMA.

Table 1. Temperatures for mixing the HMA and the WMA

\begin{tabular}{lcc}
\hline & $\begin{array}{c}\text { HMA } \\
\text { Temperature } /{ }^{\circ} \mathrm{C}\end{array}$ & $\begin{array}{c}\text { WMA } \\
\text { Temperature } /{ }^{\circ} \mathrm{C}\end{array}$ \\
\hline Asphalt binder & 160 & 160 \\
Aggregate & 170 & 135 \\
Mixing & 165 & 135 \\
\hline
\end{tabular}

\section{Mixing process and TSP sampling}

The mixing process was manually carried out, using an open mixer apparatus with a flame-heating system. First, the hot aggregate was added to the mixer and blended for 
$30 \mathrm{~s}$, and then the hot asphalt binder was introduced and the mixture was blended for $270 \mathrm{~s}$ more.

TSP samples were collected by filtration of the ambient air through the quartz fiber filter ${ }^{9}$ ( $47 \mathrm{~mm}$ diameter), using a conventional pump air sampler $\left(34 \mathrm{~L} \mathrm{~min}^{-1}\right)$. The filter holder was placed $30 \mathrm{~cm}$ above the mixer.

The mixing procedure in laboratory normally takes five min, thus sampling was performed during this time. Sampling was carried out twice for each type of asphalt mixture (WMA and HMA) and the samples obtained in each case were extracted together, in order to obtain enough mass for the analyses.

Extraction and analyses of the total suspended particles analytical procedure

Filters were previously heated at $800^{\circ} \mathrm{C}$ for $8 \mathrm{~h}$ to remove organic contaminants. $\mathrm{N}$-alkanes and PAH compounds were extracted from the filters with dichloromethane using a Soxhlet apparatus for $24 \mathrm{~h}$. Sample extracts were concentrated to $500 \mu \mathrm{L}$ by a rotary evaporator and $\mathrm{N}_{2}$ flux.

The extract was dissolved in a small aliquot of $n$-hexane and transferred to the top of a glass column $(30 \times 0.7 \mathrm{~cm}$ i.d.) containing $2.5 \mathrm{~g}$ of silica gel (Merck, 0.040-0.063 mm) and different solvents of increasing polarity following the procedure proposed by Gogou et al. ${ }^{11}$ The first fraction containing the n-alkanes was eluted from the silica gel column with $15 \mathrm{~mL}$ of n-hexane. PAH were eluted with a mixture of $9.4 \mathrm{~mL}$ of hexane and $5.6 \mathrm{~mL}$ of toluene and the oxygenated compounds were eluted following the procedure but are not considered in this work. This was followed by evaporation and extract reduction to dryness.

Quantitative and qualitative analyses were carried out by using gas chromatography with flame ionization detection (GC-FID, Varian 3800). A fused-silica capillary column, DB-5 $(30 \mathrm{~m} \times 0.25 \mathrm{~mm}$ I.D., $0.25 \mu \mathrm{m}$ film thickness), was used for separation. The chromatographic conditions were as follows: temperatures in the injector and detector were, respectively, $250^{\circ} \mathrm{C}$ and $290^{\circ} \mathrm{C}$; temperature ramp: $40^{\circ} \mathrm{C}(1 \mathrm{~min}) ; 40-150{ }^{\circ} \mathrm{C}\left(10^{\circ} \mathrm{C} \mathrm{min}^{-1}\right) ; 150-290^{\circ} \mathrm{C}$ $\left(5^{\circ} \mathrm{C} \mathrm{min}^{-1}\right) ; 290^{\circ} \mathrm{C}$ (30 min). Nitrogen was the carrier gas. A $1 \mu \mathrm{L}$ sample was injected in splitless mode. ${ }^{6}$ Limits of detection ranged from 0.12 to $0.39 \mathrm{ng} \mathrm{m}^{-3}$ for n-alkanes and from 0.25 to $0.79 \mathrm{ng} \mathrm{m}^{-3}$ for PAH. ${ }^{6}$

Major PAH listed by the USEPA as priority pollutants were analyzed. The PAH according to their elution order were: phenanthrene (Phe), anthracene (Ant), fluoranthene (Fla), pyrene (Pyr), benzo[a]anthracene $(\mathrm{BaA})$, chrysene $(\mathrm{Chr})$, benzo[b]fluoranthene $(\mathrm{BbF})$, benzo[k]fluoranthene $(\mathrm{BkF})$, benzo[e]pyrene $(\mathrm{BeP})$, benzo[a]pyrene $(\mathrm{BaP})$, indeno[cd]pyrene (InP), dibenzo[ah]anthracene (DBA) and benzo[ghi]perylene (BPe). Concentrations of low molecular weight PAH compounds (naphthalene, acenapthylene, acenaphthene and fluorene) were not considered in this work due to the low reproducibility of their results (recovery $\leq 50 \%$ ), probably due to the losses during sampling (blow off) or solvent removal steps. ${ }^{7}$

\section{Summary of the experimental study}

Figure 1 presents a summary of the experimental study with the WMA and the HMA.
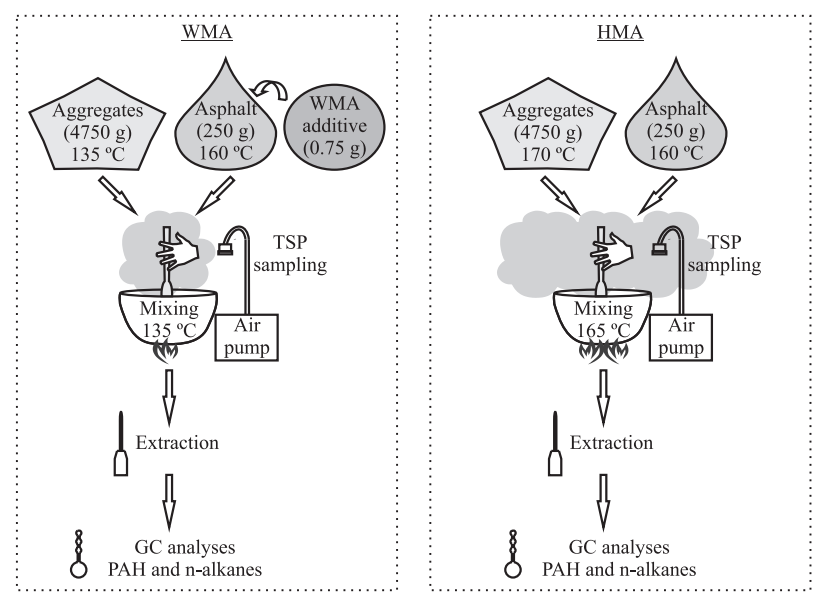

Figure 1. Summary of the experimental study with the WMA and the HMA.

\section{Results and Discussion}

\section{N-alkanes}

Figure 2 presents the profile of $n$-alkanes in the WMA and the HMA. Odd-even distribution is observed for the higher molecular mass n-alkanes.

Gas chromatograph (GC) analyses showed n-alkanes distributions from $\mathrm{C}_{14}$ to $\mathrm{C}_{35}$. The envelope of unresolved

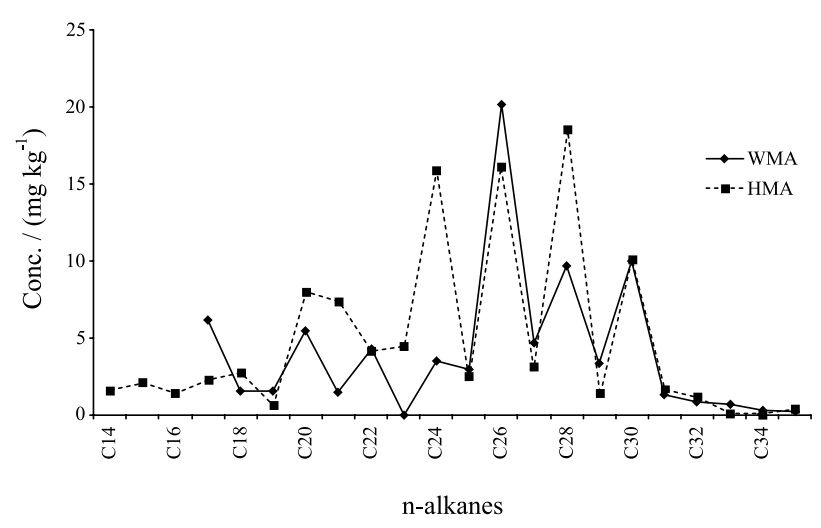

Figure 2. N-alkanes in the WMA and the HMA. 
complex mixture (UCM) of branched and cyclic hydrocarbons indicates the petroleum components. ${ }^{12}$ The $\mathrm{n}$-alkanes ranging from $\mathrm{n}-\mathrm{C}_{14}$ to $\mathrm{n}-\mathrm{C}_{35}$ presented a strong even carbon preference index ( $\mathrm{CPI}=0.4$ for the WMA and $\mathrm{CPI}=0.3$ for the HMA) and $\mathrm{C}_{\max }$ at $\mathrm{n}-\mathrm{C}_{26}$ for the WMA and $\mathrm{n}-\mathrm{C}_{28}$ for the HMA.

Blow-off (non-retention on the filter) of lower molecular mass compounds is expected due to their higher volatilities. $\mathrm{N}$-alkanes lower than $\mathrm{n}-\mathrm{C}_{23}$ are strongly depleted at temperatures higher than $15^{\circ} \mathrm{C}$ ? $^{7}$

The presence of petroleum compounds is indicated by two biomarkers, such as pristane (2,6,10,14-tetramethylpentadecane) and phytane (2,6,10,14-tetramethylhexadecane). These compounds are also found in ambient samples impacted by fossil fuels burning emissions. ${ }^{6}$ Their concentrations in the filters were 0.9 and $1.5 \mathrm{mg} \mathrm{kg}^{-1}$ for the WMA, and 1.9 and $2.8 \mathrm{mg} \mathrm{kg}^{-1}$ for the HMA.

The total content of $\mathrm{n}$-alkanes was $78 \mathrm{mg} \mathrm{kg}^{-1}$ for the WMA and $106 \mathrm{mg} \mathrm{kg}^{-1}$ for the HMA, these representing 1950 and $26454 \mathrm{ng} \mathrm{m}^{-3}$, respectively, in the ambient air.

$\mathrm{N}$-alkanes in samples collected near an asphalt plant in Algiers, Africa, presented $\mathrm{C}_{\max }=\mathrm{n}-\mathrm{C}_{18}$ and ranged from 135 to $206 \mathrm{ng} \mathrm{m}^{-3}$. Higher concentration attributed to the asphalt production was found in the vicinities, ranging from $\mathrm{n}-\mathrm{C}_{17}$ to $\mathrm{n}-\mathrm{C}_{20},{ }^{4}$ whereas the results in the present study show that n-alkanes concentrations during asphalt tests in laboratory are significantly higher than those found in the ambient atmosphere in Algiers.

\section{PAH}

HMA samples did not indicate the presence of PAH, except low concentrations of phenanthrene. Due to the low vapor pressure values of these compounds (from $1.6 \times 10^{-2}$ to $1.4 \times 10^{-6} \mathrm{~Pa}$, at $20{ }^{\circ} \mathrm{C}$ ), they are usually found mostly in gas-phase fraction. ${ }^{7}$ Temperatures higher than $35{ }^{\circ} \mathrm{C}$ volatilize three-to-four benzene-ring PAH, thus temperatures even higher as that used in the hot mix $\left(160{ }^{\circ} \mathrm{C}\right)$ are responsible for the lack of the larger PAH in the HMA samples. The literature points out that PAH compounds volatilize at high temperatures used in paving operations, such as between 150 and $180^{\circ} \mathrm{C}$, creating the potentialfor inhalation exposure. ${ }^{13}$

Figure 3 depicts the PAH found in the samples collected during the preparation of the WMA. Among the 16 priority $\mathrm{PAH}$, ten compounds were determined. Benzo[b] fluoranthene (1944 $\mathrm{ng} \mathrm{kg}^{-1}$ ) and benzo[a]anthracene (1127 $\mathrm{ng} \mathrm{kg}^{-1}$ ) were the major PAH. Despite the priority PAH being considered dangerous to human health, mainly the larger ones, ${ }^{7}$ previous literature reports that high concentrations of larger molecular mass compounds may contribute to the physical properties of the asphalt binder, since they can influence the binder flexibility. ${ }^{14}$

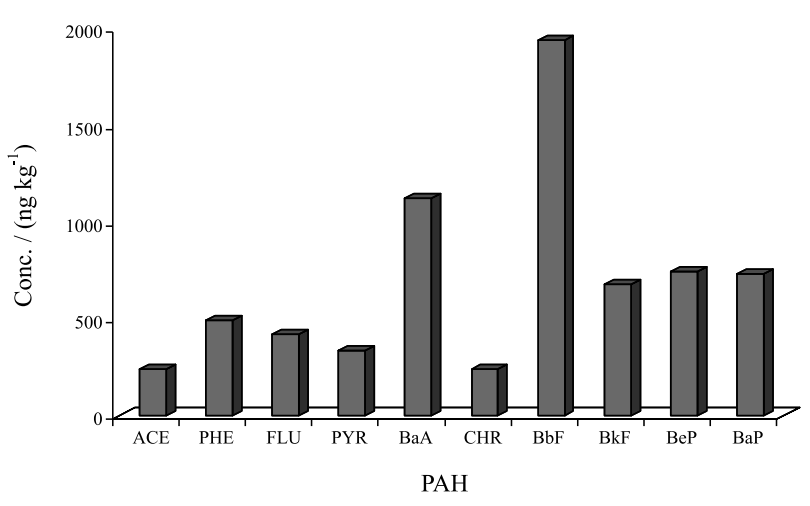

Figure 3. PAH in the WMA.

Other studies also used filter cassettes for sampling PAH from bituminous materials or asphalt mixtures. Heikkilä et al. ${ }^{9}$ report the results of laboratory studies concerning asphalt binder fumes at $170-180{ }^{\circ} \mathrm{C}$, in which fluorene, phenanthrene and pyrene were found in the particulate phase and phenanthrene and naphthalene in the gaseous one, besides the methylated derivatives compounds.

In another study, in a Swedish road, three to fourring PAH were found, dominating over unsubstituted compounds. Some PAH were below the limit of detection, but the exposure of the asphalt workers to pyrene was between 4 and $200 \mathrm{ng} \mathrm{m}^{-3}$, which was higher than that found in the Stockholm heavy traffic roads $\left(10-30 \mathrm{ng} \mathrm{m}^{-3}\right) .^{15}$

Yassaa $\mathrm{et} \mathrm{al}^{4}$ studied the composition of atmospheric particulate matter collected in Algiers and observed the strong influence of emissions from the asphalt plant. The most abundant PAH were fluoranthene and pyrene $(25 \%)$.

Although these studies used filter cassettes, protocols for sample collection and analysis varied in different countries, suggesting the need for standardization. ${ }^{10,16}$ Different procedures to collect samples and differences among asphalt binders, sample temperature and other variables might make it difficult to compare the results with other studies. ${ }^{16}$

Fernandes et al. ${ }^{17}$ also studied a Brazilian asphalt binder, but with a 50/70 penetration grade. The authors developed a method for PAH extraction in the asphalt binder by matrix solid-phase and gas chromatography, in which fifteen PAH were found in the extracts and $\mathrm{B}[\mathrm{g}, \mathrm{h}, \mathrm{i}] \mathrm{P}$ was the most abundant.

In this work, the four and five-ring PAH benzo[a] anthracene and benzo[b]fluoranthene were the most abundant. Three-ring PAH compounds are considered 
highly toxic and less mutagenic and four-ring PAH are known to be mutagenic and carcinogenic. ${ }^{17}$ Overall, different epidemiological studies indicate that asphalt fumes cause carcinogenic effects in humans, and the lungs is the target organ. ${ }^{18}$ Nevertheless, the literature ${ }^{19}$ points out that the carcinogenic activity of asphalt fumes cannot be explained only on the basis of their PAH content and hypothesizes that the co-carcinogenic effects of aliphatic hydrocarbons could be responsible for part of the carcinogenic activity.

\section{Conclusions}

The solvent extractable n-alkanes and PAH present in TSP collected during the preparation of asphalt mixes were characterized using GC-FID techniques.

$\mathrm{N}$-alkanes in the samples collected during the preparation of the WMA and the HMA presented $\mathrm{C}_{\max }$ at $\mathrm{n}-\mathrm{C}_{26}$ and $\mathrm{n}-\mathrm{C}_{28}$, respectively. The two biomarkers pristane and phytane were also determined, and their concentrations in the filters were higher for the HMA than for the WMA. Also, the total content of $\mathrm{n}$-alkanes was higher for HMA than for WMA.

For the WMA, among the 16 priority $\mathrm{PAH}$, ten compounds were determined; benzo[b]fluoranthene and benzo[a]anthracene were the major PAH. Hence, in this work, the most abundant were four and five-ring PAH, known to be mutagenic and carcinogenic. The higher temperature during the HMA preparation volatilize larger PAH, with the determination only of phenanthrene, increasing the potential for inhalation exposure. In this context, although large PAH were found in the WMA, the lower production temperatures of this paving technique may reduce the PAH concentration in the TSP, in comparison to conventional HMA.

Moreover, sample collection and analysis of PAH varied in different countries, rendering difficult to compare the results and suggesting the need for standardization.

\section{Acknowledgments}

The authors thank CAPES (Coordenação de Aperfeiçoamento de Pessoal de Nível Superior), FAPESP (Fundação de Amparo à Pesquisa do Estado de São Paulo) and $\mathrm{CNPq}$ (Conselho Nacional de Desenvolvimento Científico e Tecnológico) for the grants (Demanda Social, project \# 2006/51476-1 and project \# 305815/2009-1, respectively). The authors also thank Quimigel Ltda. Divisão Química for providing the surfactant additive.

\section{References}

1. Asphalt Institute; The Asphalt Handbook $-M S-4,7^{\text {th }}$ ed., Asphalt Institute: Lexington, KY, 2007.

2. Bernucci, L.; Motta, L.; Ceratti, J. A.; Soares, J.; Pavimentação Asfáltica: Formação Básica para Engenheiros, Petrobras/ ABEDA, 3a. ed., Rio de Janeiro, RJ, Brasil, 2010

3. National Institute for Occupational Safety and Health; Health Effects of Occupational Exposure to Asphalt: Hazard Review, U.S. Department of Health and Human Services, 2000.

4. Yassaa, N.; Meklati, B. Y.; Cecinato, A.; Marino, F.; Chemosphere 2001, 45, 315.

5. Schreiner, C. A.; Regul. Toxicol. Pharm. 2011, 59, 270.

6. Vasconcellos, P. C; Souza, D. Z.; Sanchez-Ccoyllo, O.; Bustillos, J. O. V.; Lee, H.; Santos, F. C.; Nascimento, K. H.; Araújo, M. P.; Saarnio, K.; Teinila, K.; Hillamo, R.; Sci. Total Environ. 2010, 408, 5836.

7. Ravindra, K.; Sokhi, R.; Van Grieken, R.; Atmos. Environ. 2008, 42, 2895.

8. Gasthauer, E.; Mazé, M.; Marchand, J. P.; Amouroux, J.; Fuel 2008, 87, 1428.

9. Heikkilä, P. R.; Väänänen, V.; Hämeilä, M.; Linnainmaa, K.; Toxicol. in Vitro 2003, 17, 403.

10. Prowell, B. D.; Hurley, G. C.; Warm-Mix Asphalt: Best Practices, National Asphalt Pavement Association: Lanham, 2007.

11. Gogou, A.; Apostolaki, M.; Stephanou, E.; J. Chromatogr. 1998, 799, 215.

12. Oros, D. R.; Simoneit, B. R. T.; Appl. Geochem. 2001, 16, 1513.

13. Keshava, N.; Ong, T-M.; Mutat. Res. 1999, 437, 175.

14. Pinheiro, L. S.; Fernandes, P. R. N.; Cavalcante, R. M.; Nascimento, R. F.; Soares, J. B.; Soares, S. A.; Freire, J. A. K.; J. Braz. Chem. Soc. 2009, 20, 222.

15. Järvholm, B.; Nordström, G.; Högstedt, B.; Levin, J.; Wahlström, J.; Östman, C.; Bergendahl, C.; Scand. J. Work Environ. Health. 1999, 25, 131.

16. Ekström, L.; Kriech, A.; Bowen, C.; Johnson, S.; Breuer, D.; J. Environ. Monit. 2001, 3, 439.

17. Fernandes, P. R. N.; Soares, S. A.; Nascimento, R. F.; Soares, J. B.; Cavalcante, R. M.; J. Chromatogr. Sci. 2009, 47, 789.

18. Binet, S.; Pfohl-Leszkowicz, A.; Brand, H.; Lafontaine, M.; Castegnaro, M.; Sci. Total Environ. 2002, 300, 37.

19. Rogge, W. F.; Hildemann, L. M.; Mazurek, M. A; Cass, G. R.; Environ. Sci. Technol. 1997, 31, 2726.

Submitted: June 21, 2011 Published online: July 19, 2012

FAPESP has sponsored the publication of this article. 